\title{
The occurrence of varicella after zoster vaccination in a patient with rheumatoid arthritis receiving tofacitinib
}

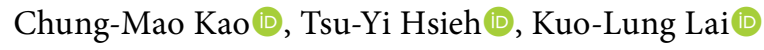 \\ Department of Internal Medicine, Division of Allergy, Immunology and Rheumatology, Taichung Veterans General Hospital, \\ Taichung City, Taiwan
}

Tofacitinib is a Janus kinase (JAK) 1 and 3 inhibitor approved for the treatment of rheumatoid arthritis (RA). ${ }^{1}$ JAK1 is associated with the receptors for interferons (IFNs) which are involved in the immunity against viral infections. ${ }^{2,3}$ Tofacitinib modulates the varicella-zoster virus (VZV)-specific type I helper T cells' response to VZV by reducing IFN- $\gamma$ production and the proliferation of specific $\mathrm{T}$ cells in a dose-dependent manner. ${ }^{4,5}$ Common adverse events of tofacitinib include herpes zoster. ${ }^{6}$ Zoster vaccine is one type of live-attenuated vaccines, of which the administration concurrent with the use of tofacitinib is suggested to be avoided.?

A 30-year-old female patient diagnosed with RA was administered with tofacitinib $5 \mathrm{mg}$ twice daily. She did not have history of varicella at a young age. Due to personal reasons, she received a single dose of zoster vaccine without consultation with her rheumatologist. Two weeks after the vaccination, itchy vesicles and papules originated from the perioral region and around the vaccine injection site in the left deltoid region (Figure 1). Subsequently, the vesicles and papules rapidly extended to the forehead, cheeks and chin (Figure 2). Varicella in association with zoster vaccination was considered, so tofacitinib was discontinued. She was admitted to the isolation ward and given intravenous acyclovir $500 \mathrm{mg}$ every 8 h. On hospital Day 1, the results of blood survey were as follows: white blood cell

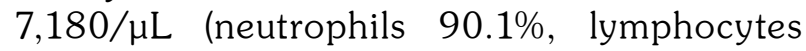
$3.5 \%$ ), hemoglobin $11.3 \mathrm{~g} / \mathrm{dL}$, platelet count $251,000 / \mu \mathrm{L}$, aspartate aminotransferase $56 \mathrm{U} / \mathrm{L}$, alanine aminotransferase

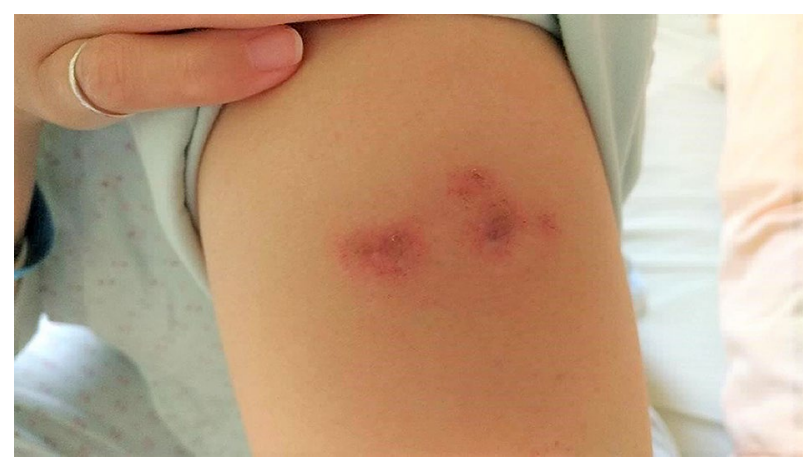

Figure 1. Several vesicles and papules occurred in a group around injection site of zoster vaccine in left deltoid region. Lesions had been crusted when photograph was taken.

Received: June 22, 2020 Accepted: July 16, 2020 Published online: January 14, 2021

Correspondence: Kuo-Lung Lai, MD. Department of Internal Medicine, Division of Allergy, Immunology and Rheumatology, Taichung Veterans General Hospital, 40705 Taichung City, Taiwan. Tel: +886-4-2359-2525 / 3354 e-mail: kllaichiayi@yahoo.com.tw

\section{Citation:}

Kao CM, Hsieh TY, Lai KL. The occurrence of varicella after zoster vaccination in a patient with rheumatoid arthritis receiving tofacitinib. Arch Rheumatol 2021;36(2):305-307. 


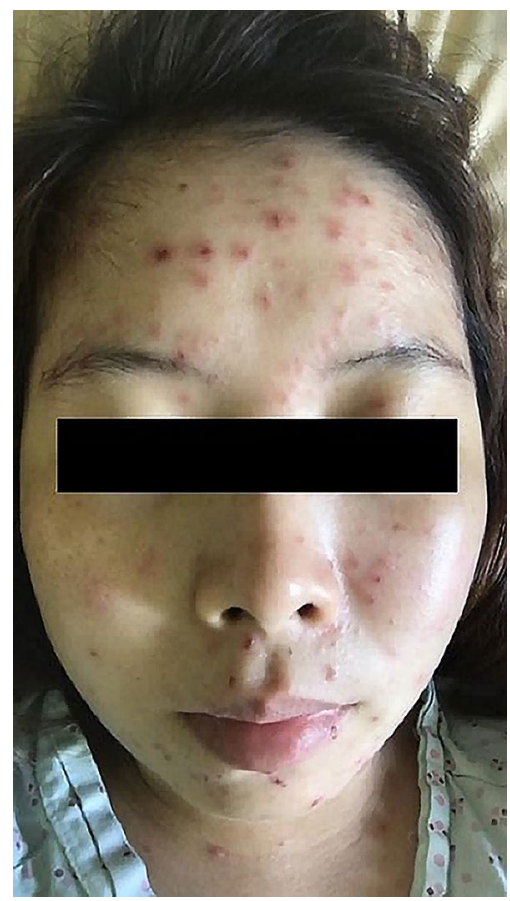

Figure 2. Multiple vesicles and papules occurred over forehead, cheeks, chin and neck. Some lesions had become crusted.

$61 \mathrm{U} / \mathrm{L}$, blood urea nitrogen $10 \mathrm{mg} / \mathrm{dL}$, and creatinine $0.74 \mathrm{mg} / \mathrm{dL}$. A serological survey revealed an elevation of $\mathrm{VZV}$-immunoglobulin (Ig) $M$ (ratio=3.887, reference positive $\geq 1.1$ ) and VZV-IgG (ratio $=6.366$, reference positive $\geq 1.1$ ) levels, along with normal herpes simplex virus (HSV)-I IgG and HSV-II IgG levels. During the first three days of hospitalization, the vesicles continued to extend to the skin covering the neck, upper chest and upper back, which was accompanied by a fever. The fever later subsided and the vesicles stopped their progression and began to become crusted during hospital Day 3. After a seven-day course of intravenous acyclovir therapy, the patient was allowed to be discharged from the isolation ward. No VZV reactivation was observed during the subsequent six-month outpatient department visits. A written informed consent was obtained from the patient.

To our knowledge, this is the first case in the English literature which demonstrates the risk of post-zoster vaccination varicella in a tofacitinib user. The 2019 European
League Against Rheumatism recommendations stated that live-attenuated vaccines may be considered in patients with rheumatic diseases but they should be avoided during immunosuppression. ${ }^{7}$ Zoster vaccination with caution in appropriately-selected patients with rheumatic diseases can be both immunogenic and safe. ${ }^{8}$ For the purpose of safety, it is suggested that the zoster vaccine should be administered four weeks prior to the initiation of biologic or targeted synthetic disease-modifying antirheumatic drugs. ${ }^{7}$ Our case has demonstrated an adverse event of zoster vaccination during tofacitinib treatment. The disease course of zoster vaccine-induced varicella seemed benign and the patient displayed a good response to intravenous acyclovir treatment.

\section{Declaration of conflicting interests}

The authors declared no conflicts of interest with respect to the authorship and/or publication of this article.

\section{Funding}

The authors received no financial support for the research and/or authorship of this article.

\section{REFERENCES}

1. Hodge JA, Kawabata TT, Krishnaswami S, Clark JD, Telliez JB, Dowty ME, et al. The mechanism of action of tofacitinib - an oral Janus kinase inhibitor for the treatment of rheumatoid arthritis. Clin Exp Rheumatol 2016;34:318-28.

2. Pesu M, Laurence A, Kishore N, Zwillich SH, Chan G, O'Shea JJ. Therapeutic targeting of Janus kinases. Immunol Rev 2008;223:132-42.

3. O'Sullivan LA, Liongue C, Lewis RS, Stephenson $\mathrm{SE}$, Ward AC. Cytokine receptor signaling through the Jak-Stat-Socs pathway in disease. Mol Immunol 2007;44:2497-506.

4. Asanuma H, Sharp M, Maecker HT, Maino VC, Arvin AM. Frequencies of memory T cells specific for varicella-zoster virus, herpes simplex virus, and cytomegalovirus by intracellular detection of cytokine expression. J Infect Dis 2000;181:85966.

5. Almanzar G, Kienle F, Schmalzing M, Maas A, Tony HP, Prelog M. Tofacitinib modulates the VZV-specific $\mathrm{CD} 4+\mathrm{T}$ cell immune response in vitro in lymphocytes of patients with rheumatoid arthritis. Rheumatology (Oxford) 2019;58:2051-60. 
6. Pfizer Inc.: Xeljanz prescribing information. Available at: http://labeling.pfizer.com/ShowLabeling. aspx?id=959. [Last revised: December 2019].

7. Furer V, Rondaan C, Heijstek MW, Agmon-Levin N, van Assen S, Bijl M, et al. 2019 update of EULAR recommendations for vaccination in adult patients with autoimmune inflammatory rheumatic diseases.
Ann Rheum Dis 2020;79:39-52.

8. Winthrop KL, Wouters AG, Choy EH, Soma K, Hodge JA, Nduaka $\mathrm{CI}$, et al. The safety and immunogenicity of live zoster vaccination in patients with rheumatoid arthritis before starting tofacitinib: A randomized phase II trial. Arthritis Rheumatol 2017;69:1969-77. 